\title{
As POLÍTICAS DE ATENDIMENTO PARA A INFÂNCIA NOS DOCUMENTOS DA UNESCO E SUAS IMPLICAÇÕES NAS DIRETRIZES DE ATENDIMENTO DA EDUCAÇÃO INFANTIL DO MUNICÍPIO DE GOIÂNIA*
}

Terezinha Duarte Vieira*

\section{RESUMO}

Este trabalho tem como objetivo compreender o conceito de infância da Organização das Nações Unidas para a Educação, a Ciência e a Cultura (Unesco) e perceber como essa concepção aparece nas diretrizes de atendimento da educação infantil. Para isso recorreu a estudos que delineiam a história dos diversos espaços que vêm atendendo a criança brasileira (CosTA, 1983; MERISSE, 1997; MonARCHA, 2001), buscando relacioná-los com as vicissitudes do capital. Diante dessa simbiose, elegemos a Unesco - agência internacional que desempenha o papel de elaboradora das diretrizes da educação mundializada (EvANGELISTA,1997), para analisar como essa agência entende a infância e para, sobretudo, refletir sobre a lógica que permeia as políticas de atendimento à infância dessa agência e suas implicações nas diretrizes de atendimento da educação infantil. Esse percurso nos apontou que o viés econômico que vem sustentando as reformas educacionais está imbricado na história do atendimento à criança brasileira, na medida em que, no decorrer desse atendimento, constatase a desvalorização dos profissionais que atuam com crianças, a ausência de uma política efetiva e clara de financiamento específica para essa etapa do ensino e de uma política de atendimento para construção de sujeitos críticos e $(r e)$ construtores de sua própria história.

Palavras-chave: infância; Unesco; educação mundializada; diretrizes de atendimento.

\footnotetext{
* Artigo recebido em 5/3/2006 e aprovado em 25/5/2006.

** Mestre em Educação, professora da Rede Municipal de Goiânia e da Universidade Estadual de Goiás. E:mail: teteterete@ bol.com.br
} 
OS AGENTES DELINEADORES DAS POLÍTICAS DE ATENDIMENTO À INFÂNCIA: IGREJA, MÉDICOS E FILANTRÓPICOS

As políticas públicas para a educação da infância podem ser observadas por meio das diversas formas que a criança brasileira pertencente à classe popular vem sendo atendida. A relação entre políticas para a educação da infância com os diferentes espaços de atendimento da criança de classe popular implica ainda a necessidade de resgatar e compreender os diversos espaços e concepções que a criança popular tem vivenciado suas infâncias (Merisse, 1997).

O processo histórico vivenciado por essas crianças, sobretudo aquelas que não tiveram abrigo familiar, pode ser o início do debate para a compreensão das origens de políticas para a infância brasileira. Por outro lado, vale também comparar concepções, princípios de políticas que embasaram espaços institucionais vividos por crianças de classe social e econômica favorecida.

Durante o século XIX, em pleno período colonial, o espaço institucional que abrigava crianças de classes populares tinha como proposta de atendimentos a acolhida de crianças com até doze anos de idade (Costa, 1983). Entretanto, nesse mesmo período, os estudos de (MonARCHA, 2001) assinalam que os primeiros jardins de infância tiveram como diretrizes educacionais o atendimento à criança da elite brasileira, em uma perspectiva escolar. Havia nesse período a presença de dois tipos de atendimentos para as crianças, um para as de classe popular e outra para as de elite. A primeira abrigava, acolhia, guardava e cuidava de crianças abandonadas, ao passo que a segunda tinha como propósito ensinar.

Os estudos de (Merisse, 1997), (Costa, 1983) e (Monarcha, 2001) permitem perceber que as políticas para a educação da infância têm sido tecidas desde a sua origem por diferentes políticas para a educação da infância, de acordo com as classes sociais. Compreender as políticas para a educação da infância implica sobretudo, refletir sobre uma sociedade dividida e caracterizada por classes sociais distintas.

Merisse (1997) desenvolveu seus estudos postulando que, em meio à luta e no seio da sociedade capitalista, emerge também o embate das diferentes classe sociais, bem como políticas para a educação da infância que se entrelaçam, coadunam-se e formatam-se. 
A infância pobre institucionalizada que fora interesse de grupos como a Igreja, os higienistas e demais instituições evidenciam que as políticas para o atendimento à criança desse período representavam interesses religiosos, médicos e de iniciativa privada. Com o intuito do cuidado e da guarda, essas políticas visavam à acomodação, à acolhida, ao disciplinamento e à regularização de corpos.

Como essas iniciativas tinham caráter filantrópico, religioso e assistencial, as concepções presentes no atendimento das crianças dessas instituições implicavam a acomodação e o ajustamento de indivíduos para a adequação e adaptação de uma sociedade tanto escravocrata como colonial, imperial e republicana. Significa que, embora o Estado estivesse ausente como poder público e como inexistia uma legislação específica para a infância, as perspectivas no atendimento às crianças pobres estavam voltadas para a manutenção e o ajustamento do indivíduo ao status quo. Tratava-se de uma participação meio velada por meio da filantropia, da religiosidade e do assistencialismo.

Com o processo de urbanização, industrialização e desenvolvimento, o Estado assumiu claramente seus interesses e passou a apontar diretrizes e políticas de atendimento à infância. Como desdobramento, promulgaram-se no país as primeiras legislações que legitimaram a proteção e o cuidado à infância. Ao determinar e oficializar leis para a infância, o Estado parece assumir seu papel de protagonista, pelo menos no campo legal, para atender às crianças de classe social popular.

Desde a colonização brasileira, a educação da infância caminhou junto com o desinteresse daqueles que estiveram no poder. No entanto, o Estado, no contexto da redemocratização brasileira, assumiu a questão da educação infantil no campo legal como uma de suas prioridades democráticas. É pelo preceito de direito e de cidadania que as legislações federais e políticas públicas para a infância emergiram nos diversos setores sociais, como no campo do direito, do trabalho, do social e, sobretudo, do educacional.

\section{A EDUCAÇÃO DA INFÂNCIA NO FOCO DAS AGÊNCIAS INTERNACIONAIS}

As políticas para a educação da infância, como leis públicas, tornam-se destaque nas agendas governamentais na década de 1990. Destacam-se a Constituição Federal de 1988 (BRASIL, 1988), Estatuto 
da Criança e do Adolescente (ECA; BRASIL, 1990) e Lei de Diretrizes e Bases Educacional (LDB; BRAsIL, 1996), que oficializam a educação da infância como um direito da criança cidadã.

O reconhecimento em termos de políticas públicas para a infância parece representar um marco para as políticas públicas da educação infantil. Representa um divisor de águas que demarcou, de um lado, as políticas de atendimento implementadas por entidades particulares como a Igreja, médicos higienistas e a rede privada; e de outro, com a redemocratização do Brasil, o Estado, junto às agências internacionais, assumiu o papel de instituidor de direito e políticas para a infância, no campo das legislações brasileiras.

As significativas alterações que ocorreram na legislação brasileira instituíram inovações e mudanças nas políticas de atendimento de crianças de zero a seis anos de idade. Representam os desdobramentos das reformas educacionais implantadas, sobretudo, após a década de 1990. Gentili (1998) demonstra que elas tiveram início nos anos 1970 e se cristalizaram na década de 1980, por intermédio das elites políticas econômicas locais. No Brasil, a implementação desse conjunto de idéias iniciou-se no governo de Itamar Franco, mas sua consolidação ocorreu no governo de Fernando Henrique Cardoso (Shiroma, 2000).

As políticas para o atendimento da educação da infância refletem o processo de transformações sociais, políticas, econômicas que vêm ocorrendo na humanidade nas ultimas décadas. Autores como (GENTILI, 1998), (Shiroma, 2000), (Frigotto, 1998, 2000), entre outros, têm revelado que as mudanças ocorridas na educação, desde a década de 1970, estão relacionadas com o processo de expansão e consolidação do capital.

Gentili (1998) explica que as reformas econômicas que aconteceram na década de 1990, como alternativa para a superação da crise do sistema capitalista, apresentam uma notável homogeneidade com as reformas educacionais e obedecem aos mesmos princípios presentes no conjunto de idéias econômicas, utilizados para a superação da crise econômica e utilizados, nas últimas décadas, no campo da educação.

Nesse contexto, redefinem-se os rumos da educação em uma perspectiva econômica e mundializada. Ocorrem mudanças advindas da livre negociação entre as nações, e, ao mesmo tempo, implicam a transferência de responsabilidades sociais que antes pertenciam ao poder público, o Estado nacional, para a esfera do mercado. A educação, nessa lógica, constitui interesse da economia e do mercado. 
A Conferência Mundial de Educação para Todos (UnEsCo, 1990a) representou, nessa conjuntura, o evento que marca a redefinição da educação e aponta diretrizes para a educação do século XX. Agências internacionais - como Unesco, Banco Mundial, Fundo das Nações Unidas para a Infância (Unicef), Programa das Nações Unidas para o Desenvolvimento (Pnud) - patrocinam eventos internacionais e elaboram diretrizes educacionais para os países da América Latina com o propósito de reduzir o analfabetismo e acabar com a violência e a pobreza.

\section{Políticas PARA A EDUCAÇão da INFÂNCIA NOS DOCUMENTOS DA UNESCO}

A Unesco, criada após a Segunda Guerra Mundial para contribuir para a manutenção da paz e da segurança dos povos e das nações por meio da educação, da ciência e da cultura, assumiu o papel de agência articuladora, elaboradora de diretrizes e de ações para a realização de uma educação mundializada. O slogam educação para todos marca, na educação brasileira, um momento de alterações nas políticas educacionais em uma perspectiva econômica descentralizadora e municipalizada, sobretudo no campo da educação da infância.

A articulação para difundir uma concepção mundializada, na mesma perspectiva do livre comércio, já se fazia presente no período de 1971 a 1972, quando a Unesco constituiu sua $1^{a}$ Comissão Internacional para o Desenvolvimento da Educação para orientar os diferentes governos a elaborarem propostas de educação às vésperas do segundo decênio do desenvolvimento. ${ }^{1}$ Para difundir uma concepção de educação baseada na ordem mundial, caracterizada pela democracia dos comércios e da liberdade entre indivíduos e nações, o Relatório Faure (1974) desenvolveu princípios e conceitos que já se faziam presentes nos fundamentos da Unesco.

A comissão, que esteve sob a coordenação de Edgar Faure, expresidente da Educação Nacional da França, teve como finalidade colaborar com os governos nacionais na formulação de estratégia para o desenvolvimento da educação, definindo orientações a serem dadas à cooperação internacional no que tange à educação e contribuindo para o estabelecimento de linhas de ação da Unesco no Segundo Decênio das Nações Unidas para o Desenvolvimento (Evangelista, 1997).

Evangelista (1997) destaca que, após sua elaboração, o Relatório Faure foi submetido ao processo de apreciação, de comentário e de 
debate pelos Estados-membros, pelo Conselho Executivo e pela Conferência Geral. Segundo a autora, esse movimento revela a participação das nações no processo de determinações da educação para $o$ segundo decênio, e, ao mesmo tempo, mostra o espaço de discussão que acontece na agência no processo de seleção e de elaboração de políticas educacionais, enfoque esse já apontado por Silva (1999).

A concepção de infância proclamada no contexto histórico do Segundo Decênio do Desenvolvimento - que teve como princípio o livre comércio entre as nações e a liberdade dos indivíduos - é instituída com a seguinte compreensão:

Uma educação da pequena infância, aproveitando a contribuição da ação do meio sobre a criança de maneira a assegurar as condições favoráveis para o seu pleno desenvolvimento, tanto físico como o mental. (FAURE, 1974, p. 225)

Por esse prisma, a infância é reconhecida como um período de vida favorável para o desenvolvimento do homem. Ademais, a concepção assumida no relatório distancia-se da visão religiosa vigente no período colonial acerca da infância, que era entendida como um período de pureza, de inocência e de incompletude do ser humano. A distância entre esses dois modos de conceber a infância é marcada também pelo modo como as crianças vivem esse período.

Vistas como seres puros, inocentes e incompletos que não participavam da vida ativa e produtiva da sociedade, as crianças, nessa compreensão de infância, viviam e aprendiam com os adultos em diferentes espaços sociais. Diferentemente dessa perspectiva, o Relatório Faure (1974) entende a infância como um período favorável para "preparar o futuro adulto para diversas formas de autonomia" (p. 225), e a infância passou a ter lugar específico para esse preparo - uma instituição infantil.

De acordo com Faure (1974), "Os primeiros anos escolares podem ser consagrados a aprender a aprender e deveriam visar o desenvolvimento social e afetivo como desenvolvimento intelectual" (p. 276).

A educação das crianças em espaços escolares já estava presente nas concepções dos higienistas que, de um lado, tiveram o papel de intelectuais difusores dos princípios liberais e da sociedade burguesa, mas, de outro, conseguiram combater o alto índice de mortalidade infantil 
por meio do avanço das ciências e vacinas (CostA, 1983). No entanto, na perspectiva de uma economia transnacional, a configuração do espaço escolar que as crianças freqüentavam é diferente, conforme assinala Faure (1974):

Trata-se, pois, de organizar duma maneira flexível e livre a educação de crianças em idade pré-escolar (a partir de dois ou três anos), procurando meios de associar a família e a comunidade. Trata-se também de aproveitar técnicas de comunicação de massas, que podem prestar grandes serviços sempre que se tenha a preocupação de estender, sem perda do tempo, o ensinamento pré-escolar a um grande número de crianças, especialmente às que vivem em ambientes de fraca impregnação cultural. (p. 284)

A atenção, o cuidado e a educação na infância, na perspectiva de moldar e domesticar o ser humano para viver na sociedade burguesa no final do século XIX e início do XX, passaram a ter o caráter de preparação e ensinamento para esse novo momento social que se baseava na idéia de democratização da educação de crianças. Essa perspectiva também não se limitava ao espaço institucional e apontava diferentes mecanismos de acesso a um número significativo de crianças.

Contudo, é preciso recuperar alguns dados significativos da década de 1970 no Brasil. Kramer (1995) mostra que, segundo o Diagnóstico preliminar da educação pré-escolar, em 1975, a população de zero a seis anos era de cerca de 21 milhões de crianças. Deste total, apenas $3,51 \%$ da população em idade pré-escolar eram atendidos, e $44 \%$ daquele percentual refere-se a matrículas em instituições particulares. Nesse sentido, segundo Kramer, "a maioria das crianças que recebem educação pré-escolar provém das classes médias e altas, ficando alijadas a quase totalidade das crianças que se originam de classes dominadas" (p. 90).

Esses dados mostram que inexistia a democratização da pré-escola preconizada no Relatório Faure e revelam que os programas de massa, livres e flexíveis não alcançaram a totalidade da demanda existente na política de atendimento naquele momento. Outro aspecto que se pode perceber nos programas pré-escolares propostos no relatório, à luz dos estudos de Kramer (1995) e Barbosa (1997), é o caráter de uma educação compensatória como mecanismo de superação da miséria e da pobreza da população. 
A importância dada à infância como um período de vida propício ao desenvolvimento físico e mental, conforme prescreve o Relatório Faure, encontra-se em sintonia com a perspectiva de infância que aparece no Relatório Delors, elaborado por uma Comissão Internacional sobre Educação para o Século XXI, composta por 14 especialistas de algumas partes do mundo - não se incluindo nessa lista o Brasil -, tendo Jacques Delors como presidente da comissão. O relatório foi intitulado Educação - um tesouro a descobrir.

A perspectiva de uma educação pré-escolar para crianças desde a idade de dois ou três anos - que aparece no Relatório Faure com objetivo de preparação do futuro adulto - está também presente no Relatório Delors como um benefício educacional que garantiria a permanência da criança nas escolas em etapas escolares posteriores. No documento de Delors (1999) existe a seguinte afirmativa:

Esperemos que se iniciem, ou continuem, os esforços para multiplicar as possibilidades de aprendizagem oferecidas à primeira infância no quadro de um movimento que pretende fazer da educação básica universal uma realidade. (p. 130)

A educação da infância, nessa perspectiva, está aliada à idéia da aprendizagem. $\mathrm{O}$ sentido da aprendizagem de que trata esse documento pode ser observada na política educacional da educação para todos, elaborada na Conferência Mundial de Educação para Todos que aconteceu em Jomtien, na Tailândia, no início da década de 1990. A aprendizagem é tratada, entre os objetivos da educação para todos, por meio da satisfação das necessidades básicas de aprendizagem (Nebas), as quais

compreendem tanto os instrumentos essenciais para a aprendizagem (como leitura e a escrita, a expressão oral, o cálculo, a solução de problemas) quanto os conteúdos básicos da aprendizagem (como conhecimentos, habilidades, valores e atitudes), necessários para que os seres humanos possam sobreviver, desenvolver plenamente suas potencialidades, viver e trabalhar com dignidade, participar plenamente do desenvolvimento, melhorar a qualidade de vida, tomar decisões fundamentadas e continuar aprendendo. (UNESCO, 1990a, p. 3)

Segundo o Plano de ação para satisfazer as necessidades básicas de aprendizagem (UNESCO, 1990b), os instrumentos essenciais da 
aprendizagem devem abranger a leitura, a escrita, a expressão oral, o cálculo e a solução de problemas, além dos conteúdos básicos da aprendizagem: conhecimentos, habilidades, valores e atitudes. Nesses moldes, a educação da infância parece direcionar-se para aspectos da aprendizagem que são trabalhados tradicionalmente na escola.

Esse modo de conceber a educação da infância opõe-se à proposta de uma escola infantil concebida por vários educadores e pesquisadores, entre os quais se destaca (Oliveira, 2002). Para a autora, é necessário que uma proposta pedagógica para a educação da infância estabeleça relação com a sociedade, com a comunidade e com a cultura, isto é, uma interação com o mundo onde a criança está inserida. Dessa ótica, a institucionalização da infância não se limita ao processo da escola formal, mas deve ser também um espaço para interação com diversos aspectos da realidade, como a arte, o movimento, a música, a estética, a poesia, o folclore, as brincadeiras, a cidadania, a ética, a natureza, as linguagens, entre outras dimensões sociais e culturais.

Ademais, a perspectiva educacional para a infância apontada no Relatório Delors, além de não destacar a mediação que a criança precisa estabelecer com o mundo que a cerca, necessário para o processo da construção de sua própria cultura, não aborda a idéia do mundo simbólico e do imaginário infantil, aspectos que estudiosos como Vygotsky (1998) e, mais recentemente, Kischimoto (2002) e Faria (1999), consideram essenciais para o desenvolvimento e a aprendizagem da criança.

Essas duas visões ou concepções de educação da infância diferenciam-se no tocante à conceituação da infância. A Unesco, na década de 1990, determinava que a educação da infância devia basearse na pré-escola e na perspectiva da aprendizagem escolar. Autores como Oliveira (2002), Faria (1999) e Barbosa (1997), entretanto, apontam a infância como um período de vida em que a criança constrói sua cultura, com base nas dimensões simbólica, lúdica, cultural, artística e intelectual.

Considerando então o conceito de educação da infância na perspectiva escolar e da aprendizagem, questiona-se: em que medida a educação da infância, nos moldes escolares, pode contribuir para a manutenção da paz e para a erradicação da miséria e da pobreza?

Segundo a Declaração de Aman (UNESCO, 1996), entre os resultados obtidos, meia década após a promulgação da Declaração de Jomtien (UNESCO, 1990), houve uma redução do número de crianças fora da escola e uma crescente ênfase na qualidade do ensino. "O número de crianças 
fora da escola, que havia crescido assustadoramente durante décadas, também começa a diminuir. Existem hoje menos vinte milhões de crianças em idade escolar fora da escola do que no início da década", assinala o documento (UNESCO, 1995, p. 2).

Esse dado mostra que a idéia do desenvolvimento da paz, por meio da educação, princípio da criação da Unesco, distancia-se das políticas educacionais nas últimas décadas do século XX. Os princípios de criação da agência estabelecem que o desenvolvimento deve acontecer por meio da educação do homem e da sociedade, e a educação da infância aparece como mecanismo para preparar o futuro adulto para a autonomia. Os dados, porém, mostram que, decorridos cinco décadas de existência, as políticas educacionais da Unesco não conseguiram encontrar mecanismos para promover a inserção de todas as crianças na escola e em outras instituições educativas de qualidade.

Diante da trajetória que a Unesco vem trilhando desde sua criação, marcada pelo investimento internacional, por uma política de cooperação internacional e por ações institucionais direcionadas por declarações e relatórios, reconhece-se que estes apontam, na sua essência, importantes caminhos às nações para elas nortearem suas políticas educacionais. Por outro lado, é assustador que, no final do século XX, a Unesco trate com naturalidade o fato de vinte milhões de crianças estarem fora da escola, alegando que esse quantitativo vem diminuindo. As análises de Silva (1999) acerca da concretização dos projetos da Unesco para a área social direcionados para ações redistributivas e populistas assinalam que não se concretiza, nessa linha, um dos seus princípios, que é a universalização da escolaridade obrigatória.

Ademais, os dados apontados representam um descompasso com os princípios institucionais presentes na Convenção das Nações Unidas sobre os Direitos da Criança (Unesco, 1989), que legitima em seu artigo 29 "o direito da criança à educação, e o dever do Estado de assegurar que ao menos a educação primária seja gratuita e compulsória” (p. 12).

O direito à educação da infância é uma determinação das Nações Unidas, enunciado na Declaração de Aman, e se harmoniza com a compreensão de aprendizagem presente no Relatório Delors. Nesse sentido, a Declaração de Aman contém a seguinte afirmativa: "tanto o aprender quanto o ensinar começam no nascimento e continuam durante a vida, na medida em que os indivíduos trabalham, vivem e transmitem idéias e valores por palavras e ações" (UNESCO, 1996, p. 6 ). 
A citação implica a idéia de que o desenvolvimento individual acontece de modo contínuo e não depende só da educação formal, podendo vir a acontecer em diferentes espaços sociais de que o indivíduo faz parte. A idéia da educação da infância caminha na mesma direção, isto é, ela não precisa necessariamente de um espaço institucionalizado, nem de profissionais com formação adequada para interagir com as crianças, tampouco de propostas de trabalho com intencionalidade educativa.

A proposta implícita na Declaração de Aman para o atendimento de crianças desde o seu nascimento aproxima-se da concepção de educação da infância prescrita no Relatório Faure (1974) para a préescola, que é a "organização flexível e livre para crianças em idade préescolar" (p. 285).

Percebe-se o esforço dos organismos multilaterais para implantar programas para as famílias e outras instâncias sociais para que possam ter noções básicas sobre o atendimento de crianças pequenas em diferentes espaços, que não sejam apenas instituições infantis. Essa política, que se fundamenta no desenvolvimento infantil, contribui para os governos municipais se eximirem da responsabilidade pública de efetivar uma política de financiamento para a educação da infância que garanta a valorização do profissional, um espaço adequado para o atendimento e, sobretudo, a efetivação de uma proposta pedagógica que respeite as especificidades infantis.

Para fazer face à ausência de verba para a educação infantil, a Unesco indica programas de atendimento domiciliar, que, por sua vez, devem ser controladas pelo Estado regulador e interventor. ${ }^{2}$

Diante das proposições da Unesco para a educação da infância e das idéias que caminham na direção da sua institucionalização como direito da criança cidadã, percebem-se duas vertentes que se configuram simultaneamente no período de 1990 a 2003. A primeira abrange as determinações internacionais que, com base em uma proposta de educação transnacional e mundializada, compreendem-na segundo a perspectiva do desenvolvimento, em que o atendimento proposto é pautado pela idéia de programas de massas, flexíveis, informais e de investimento de baixo recurso financeiro, conforme está anunciado no Relatório Faure. Uma outra vertente defende um movimento de lutas sociais por espaços institucionais para que as crianças tenham direito ao acesso e ao atendimento com qualidade. 
A questão essencial a ser formulada com base nessa realidade é a seguinte: considerando que a institucionalização da infância é uma tendência contemporânea, provocada por mudanças sociais - como a inserção da mulher no mundo do trabalho e a nova configuração familiar - que levaram à necessidade de criação e à constituição de espaços institucionais para crianças de diferentes classes e grupos sociais, como garantir um espaço institucional para que essa demanda tenha como eixo central a criança?

As concepções de infância apresentadas neste trabalho baseiamse em dois blocos que se distanciam na modalidade de atendimentos, objetivos e perspectivas. Entretanto, percebe-se que ambas não deram conta sequer de suprir a necessidade do acesso a todas as crianças que pertencem a diferentes classes sociais. Também, conforme os dados apresentados, a maioria dos atendimentos que ocorrem em instituições infantis e em programas flexíveis e de massa possui baixo investimento financeiro, o que se reflete em um atendimento deficiente.

Diante dessa situação histórica de descompasso entre o estabelecimento das metas de acesso e de universalização da educação da infância e a sua concretização, a Unesco lançou-se em mais uma empreitada política para alcançar a educação da infância, conforme aconteceu na Conferência Mundial de Educação para Todos (1990). A entidade promoveu o Fórum Mundial de Educação de Dakar-Senegal, em abril de 2000, para avaliar os avanços, as lições e as deficiências da última década e também para propor novas metas a serem alcançadas. $\mathrm{Na}$ ocasião, manifestou sua preocupação com a primeira infância e a apontou como a primeira meta a ser alcançada, pois

a última década ofereceu mais evidência de que assistência e educação de boa qualidade para a primeira infância, tanto na família como em programas mais estruturados, têm impacto positivo na sobrevivência, crescimento, desenvolvimento e potencial de aprendizagem das crianças. Esses programas devem ser abrangentes concentrados em todas as necessidades da criança e envolvendo saúde, nutrição e higiene, bem como desenvolvimento psicossocial. (UNESCO, 2001, p. 18)

A proposta apresentada para o atendimento à infância na Declaração de Dakar (2001) não é mais direcionada apenas a crianças a partir dos dois ou três anos, como defende o Relatório Faure, tampouco para a idéia da aprendizagem, conforme o Relatório Delors. A idéia do 
desenvolvimento infantil volta-se agora para as "crianças de menos de quatro anos de idade" (UnesCo, 2001, p. 30). Outro aspecto apresentado nessa declaração é que o foco agora não é só o cognitivo, mas a atenção à saúde e à sobrevivência da criança, sobretudo as desfavorecidas economicamente, uma vez que o objetivo é reduzir a pobreza infantil.

A estratégia apontada para o alcance da proposta da primeira infância - preocupação da Unesco em 2000 - deve ser realizada mediante a participação de múltiplos atores, como organismos não-governamentais, pais e mães e sociedade civil. Segundo o relatório Educação e cuidados para a primeira infância - ECPI (UNESCO e OCDE, 2002), "a expressão educação e cuidado para a primeira infância indica a abordagem integrada e coerente de uma política e de serviços que incluem todas as crianças e seus pais" (p. 23). Nessa ótica, a política da ECPI, de acordo com o documento, reúne o cuidar e o educar, entendendo que

a educação e cuidados para a primeira infância inclui todas as modalidades que garantem a educação e cuidados das crianças antes da escolaridade obrigatória, independentemente da organização do espaço, do financiamento, dos horários de funcionamento ou do conteúdo de programa. (p. 23)

Nessa direção, "os serviços destinados aos bebês e às crianças mais novas são fornecidos essencialmente em centros e domicílio (centrosdomiciliares) que, no geral, exigem participação financeira dos pais" (UNESCO e OCDE, 2002, p. 78), o que implica um atendimento destituído de qualquer responsabilidade pública.

O formato apresentado no relatório ECPI (p. 76), acerca desse tipo de atendimento, é denominado de "serviços extra-escolares que podem funcionar na escola, nos centros de idade mista ou nas casas (atendimento domiciliar)". Além dessa proposta de atendimento, o relatório apresenta como complemento dos serviços gerais da ECPI.

o desenvolvimento de serviços mais flexíveis que respondam ao amplo conjunto de necessidades sociais, físicas e psicológicas das crianças e suas famílias. Esses programas tendem a incluir serviços em tempo parcial para a infância, assim como alguns serviços para os pais. (p. 122)

No tocante aos investimentos financeiros, que geralmente são limitados em vários países, o relatório indica que habitualmente devem 
ser distribuídos entre governo, pais e empresas. Nos países europeus, "a educação e a guarda das crianças são vistas essencialmente como tarefas de cunho privado, que deverão ser administradas por cada família e não como questões que exijam um sólido compromisso público" (UNESCO e OCDE, 2002, p. 129). E, na maior parte dos países-membros da Organização de Cooperação e Desenvolvimento Econômico (OCDE), os custos são compartilhados com os pais.

A idéia que permeia esses serviços para a primeira infância é, segundo o relatório ECPI, "apoio necessário para a participação das mulheres no mercado do trabalho em uma economia forte, e não como um serviço público que será benefício tanto para os pais quanto para os filhos" (p. 81). Ao mesmo tempo que assinala que a ECPI se constitui em serviços extra-escolares, indica

uma abordagem progressiva das aptidões formais (leitura e escrita). A abordagem incentiva os jogos que giram em torno da leitura e da escrita, o fato de saber contar, a teoria científica e o conhecimento dos números à medida que eles emergem naturalmente a partir dos interesses normais da criança. (p. 168)

Diante do processo da leitura e escrita, a ECPI tem como objetivo o alcance do desenvolvimento, da autonomia, da responsabilidade, do bem-estar, da autoconfiança, da cidadania, da preparação para a vida escolar e para a educação futura. É importante destacar que esses aspectos estão em sintonia com os instrumentos essenciais da aprendizagem e os conteúdos básicos da aprendizagem, o que leva a considerar que, ao mesmo tempo que formata suas propostas em ações flexíveis, livres e sem a exigência de profissionais qualificados para o atendimento, a ECPI ainda oscila entre o caráter educacional e o de ensino, uma vez que resgata conteúdos escolares.

A tendência mundializada do atendimento à criança que se apresenta nos documentos da Unesco representa os fundamentos que sustentam a política educacional, baseados na lógica econômica que veio se configurando a partir da década de 1970 e que se consolidou sobretudo nos países da América Latina nos anos 1990.

Nessa trajetória, nota-se que os Estados nacionais, por meio de representantes dos governos - que também representam a classe hegemônica -, ao longo da década de 1990, vêm renovando perante a Unesco e outros organismos multilaterais, como o Banco Mundial e o 
Fundo Monetário Internacional (FMI), o compromisso de implantar e executar a proposta de educação para todos.

Nessa conjuntura, o Brasil, por meio das reformas educacionais que aconteceram especialmente nos anos 1990, vem modificando seu sistema educacional para atender à criança e justificar o financiamento internacional que recebe dessas agências cooperadoras e financiadoras. Afinal de contas, quem financia quer retorno e lucro, porém, a principal questão é: quem de fato está pagando essa conta tão desumana?

\begin{abstract}
This study tries to understand the UNESCO concept of childhood and perceive how this concept is presented in guidelines for child education. With this in mind, the author had recourse to studies outlining the history of care for the Brazilian child, so as to relate them to the vicissitudes of life in the capital. With this symbiosis, UNESCO - the international agency whose role is to draw up guidelines at world level for education (Evangelista, 1997) - was selected to analyze how this agency conceives childhood and, in particular to reflect on the logic permeating its policies on child care and the implications for guidelines on child education. This study pointed out that the economic bias, on which educational reform is based, is built into the history of care for the Brazilian child (Costa, 1983; Merisse, 1997; Monarcha, 2001), in the sense that there has been a depreciation of those professionals working with children, as well as a lack of clear effective policies for the specific financing of this learning phase, and policies for the formation of critical and (re-)constructive subjects of their own history.
\end{abstract}

Key words: childhood; Unesco; global education; guidelines for care.

\title{
NOTAS
}

1. Segundo Evangelista (1997), o segundo decênio do desenvolvimento era o período simbólico no qual os grandes projetos da estrutura técnica financeira do comércio mundial precisavam acontecer. Para isso, era preciso que os governos nacionais aderissem a essas políticas.

2. Para Meneghel e Lamar (2002), a transferência das responsabilidades do Estado para o mercado e a comunidade colocou o Estado na nova condição de regulador, tomando por base critérios de eficiência, de competição e de qualidade advindos do mercado. Nesse contexto, as avaliações de programas e políticas sociais, incluindo as educacionais, adquirem grande importância. 


\section{REFERENNCIAS}

BARBOSA. Pré-escola e formação de conceitos: uma versão sócio-históricodialética. São Paulo, 1997. Tese (Doutorado em Educação) - Faculdade de Educação da Universidade de São Paulo.

BRASIL. Assembléia Nacional Constituinte. Constituição da República. Brasília, 1988.

. Ministério da Educação (MEC). Lei n. 8.069, de 13 de julho de 1990. Dispõe sobre o Estatuto da Criança e do Adolescente. Brasília, 1990.

Congresso Nacional. Lei n. 9.394, de 20 de dezembro de 1996. Estabelece as diretrizes e bases da educação nacional. Brasília,1996a.

COSTA, J. F. Ordem médica e norma familiar. 2. ed. Rio de Janeiro: Edições Graal, 1983.

DELORS, J. et al. Educação: um tesouro a descobrir. 2 ed. São Paulo: Cortez; Brasília: MEC/Unesco, 1999.

EVANGELISTA, E. G. dos S. Educação e mundialização. Goiânia: Ed. da UFG, 1997.

. A Unesco e o mundo da cultura. Goiânia: Editora da UFG, 2003.

FARIA, A. L. G. de. Educação pré-escolar e cultura: para uma pedagogia da educação infantil. Campinas: Ed. Unicamp, São Paulo: Cortez, 1999.

FAURE, E. et al. Aprender a ser. Lisboa-Portugal/ São Paulo-Brasil: Bertrand, 1974.

FRIGOTTO, G. Educação, crise do trabalho assalariado e do desenvolvimento: teorias em conflitos. In: FRIGOTTO, G. (Org.) Educação e crise do trabalho: perspectiva de final de século. 3 ed. Petrópolis, RJ: Vozes, 1998. p. 25-54.

Educação e a crise do capitalismo real. 4. ed. São Paulo: Cortez, 2000.

GENTILI, P. A falsificação do consenso. Simulacro e imposição na reforma educacional do neoliberalismo. 3. ed. Petrópolis, RJ: Vozes, 1998.

KISHIMOTO. T. M. Froebel e a concepção do jogo infantil. In: KISHIMOTO, T. M. (Org.) O brincar e suas teorias. São Paulo: Pioneira, 2002. p.57-78.

KRAMER, S. A política do pré-escolar no Brasil: a arte do disfarce. 5. ed. São Paulo: Cortez, 1995.

MENEGHEL, S. M., LAMAR A. R. Avaliação como construção social-reflexões sobre as políticas de avaliação da educação no Brasil. In: RISTOFF, D. I., DIAS SOBRINHO, J. (Orgs.). Avaliação democrática - para uma universidade cidadã. Florianópolis: Insular, 2002. p.145-164. 
MERISSE, A. et al. Lugares da infância: reflexões sobre a história da criança na fábrica, creche e orfanato. São Paulo: Arte \& Ciência, 1997.

MONARCHA, C. Revista do jardim da infância: uma publicação exemplar. In: MONARCHA, C. (Org.). Educação da infância brasileira: 1875-1983. Campinas: Autores Associados, 2001.p. 81-119.

OLIVEIRA. Z. R. de. Educação infantil: fundamentos e métodos. São Paulo: Cortez, 2002.

ORGANIZAÇÃO das Nações Unidas para a Ciência, Cultura e Educação (Unesco). Declaração da Convenção das Nações Unidas sobre o Direito da Criança. Brasília, 1989.

Declaração Mundial sobre Educação para Todos. Brasília, 1990a.

- Plano de ação para satisfação das necessidades básicas da aprendizagem. Brasília. 1990b.

. Declaração de Aman. Brasília, 1996.

Educação para todos: o compromisso de Dakar. Brasília, 2001.

. ORGANIZAÇÃO de Cooperação e Desenvolvimento Econômico (OCDE). Educação e cuidado na primeira infância: grandes desafios. Brasília: Ministério da Saúde, 2002.

SHIROMA, E. O. et al. Política educacional. Rio de Janeiro: DP\& A, 2000.

SILVA, M. A. Intervenção e consentimento - a política educacional do Banco Mundial. Campinas: Autores Associados/Fapesp, 1999.

VIEIRA, T. D. Concepções de infância em instituições de educação infantil. Goiânia, 2002. Monografia (Especialização em Educação Infantil) - Universidade Católica de Goiás.

A Unesco e as políticas para a educação da infância: concepções e implicações nas políticas de educação infantil no município de Goiânia (1990 a 2003). Goiânia, 2004. Dissertação (Mestrado em Educação) - Faculdade de Educação da Universidade Federal de Goiás.

VIGOTSKI. L. S. A formação social da mente: o desenvolvimento dos processos psicológicos superiores. 6. ed. São Paulo: Martins Fontes, 1998. 